\title{
Risk factors in childhood stunting in Karnataka, India, vary by geography
}

\author{
Srilakshmi M. Raj ${ }^{1,2, *, \dagger}$, Ruwanthi Ekanayake ${ }^{3, \dagger}$, Kiera Crowley ${ }^{1}$, \\ Meenakshi Bhat ${ }^{2}$, Jayarama Kadandale ${ }^{2}$ and Prabhu L. Pingali ${ }^{1}$ \\ ${ }^{1}$ Tata Cornell Institute, Cornell University, Ithaca, NY 14853, USA \\ ${ }^{2}$ Centre for Human Genetics, Electronic City, Bengaluru 560 100, India \\ ${ }^{3}$ Department of Biology and Society, Cornell University, Ithaca, NY 14853, USA
}

\begin{abstract}
Childhood stunting remains a public health concern in India. In Karnataka, the districts vary substantially in stunting prevalence. Using the NFHS-4 and AidData GEO datasets, we tested the hypothesis that 'wet' and 'dry' districts in Karnataka show different contributions to stunting. We found that for 30 environmental and health factors, Bengaluru appears to be distinct from the other districts. Using a mixed linear model approach, we found that for the entire state, and in both wet and dry districts, preceding birth interval, altitude-adjusted haemoglobin level and child age showed significant correlations with height for age (HFA). The wet districts showed an additional association between maternal age and child HFA. However, interaction effects also differed among the three conditions. Our results suggest that subtle variations should not be ignored when considering factors impacting child health outcomes.
\end{abstract}

Keywords: Childhood stunting in Karnataka, environment, genetics, nutrition, public health.

CHILDHOOD stunting, or reduced linear growth in children aged 5 years and under, has been correlated with both short-term and long-term adverse health and socioeconomic outcomes. With international efforts to reduce malnutrition only purporting to lead to a partial reduction in childhood stunting prevalence in India and elsewhere ${ }^{1}$, it is important that region- and community-specific approaches are considered to reduce the burden further and contribute to improvements in healthy growth trajectories.

Across India, 46.8 million children under 5 years of age are stunted, constituting one-third of all stunted children under 5 years globally ${ }^{2}$. This prevalence varies across states: North East India and the central states have prevalence $>30 \%$, while a majority of the remaining states have at least $20 \%$ stunting $^{3}$. With increased consumption of convenience foods, Indian children may also have accelerated 'catch-up growth' following stunting, which results in rising national obesity rates. Therefore, India is

*For correspondence. (e-mail: sri@chg.res.in)

†Equally contributed. considered to have a 'triple burden of malnutrition' characterized by calorically undernourished and overnourished individuals, with both groups at risk for disorders of micronutrient deficiencies such as anaemia, scurvy, night-blindness and rickets ${ }^{4}$. The triple burden of malnutrition has broadly resulted in several hallmarks of child growth failure (CGF), including stunting, underweight and wasting. Most recently, the three conditions have been explored jointly across India and other countries, in an effort to capture the full scope and context of $\mathrm{CGF}^{5,6}$. These analyses point to high variation within India and among countries globally in the relationship between the CGF indicators, depending on geography, environment (e.g. sanitation), socio-economic conditions and parental nutrition status. Therefore, stunting and other indicators of CGF must be studied in their local context, often at the sub-state level in India.

The importance of studying variation in stunting presentation leads us to Karnataka, India. Among the middle socio-demographic index (SDI) states, Karnataka has the greatest coefficient of variation for childhood stunting $^{6}$. For example, 9 out of its 30 districts have stunting prevalence $>40 \%$, with Koppal and Yadgir districts having $>55.5 \%$ stunting prevalence ${ }^{7}$. In contrast, Mandya district has a stunting prevalence of only $18 \%$, half of the state-wide average and three times lower than in the hardest-hit states of India.

Given this variability, we examine conditions within Karnataka that could lead to such vastly different stunting prevalence across the 30 districts, focusing on rainfall variation across the state. Shedding light on region-specific risk factors and their interactions can help make future public health efforts more targeted and effective, both in Karnataka and across India.

\section{Data and methods}

All of the data used in this study were taken from the National Family Health Survey-4 (NFHS-4) and the AidData GEO database, and data for Karnataka were extracted.

First, 30 variables from the NFHS-4 and AidData GEO datasets were collapsed into the 30 districts of Karnataka 
RESEARCH ARTICLES

Table 1. Variables included in the district-aggregated analysis of the National Family Health Survey-4 (NFHS-4) and AidData GEO datasets

\begin{tabular}{|c|c|c|c|}
\hline Variable & Description & Variable & Description \\
\hline temp1951_60 & Average temperature between 1951 and 1960 & antenatalFull & Mothers who had full antenatal care \\
\hline temp2001_10 & Average temperature between 2001 and 2010 & anemiaChild & $\begin{array}{l}\text { Children aged } 6-59 \text { months who are } \\
\text { anaemic }(<11.0 \mathrm{~g} / \mathrm{dl} ; \%)\end{array}$ \\
\hline rain1951_60 & Average rainfall between 1951 and 1960 & anemiaWomen & All women aged $15-49$ years who are anaemic $(\%)$ \\
\hline rain2001_10 & Average rainfall between 2001 and 2010 & diarrhoeaChild & $\begin{array}{l}\text { Prevalence of diarrhoea (reported) in the last } \\
2 \text { weeks preceding the survey }\end{array}$ \\
\hline ambientPollution 1990 & Inhalable particulate matter (PM) in 1990 & stuntingChild & $\begin{array}{l}\text { Children under } 5 \text { years who are stunted } \\
\text { (height-for-age; \%) }\end{array}$ \\
\hline ambientPollution 2010 & Inhalable PM in 2010 & underweightChild & $\begin{array}{l}\text { Children under } 5 \text { years who are underweight } \\
\text { (weight-for-age; \%) }\end{array}$ \\
\hline nl1992 & Night-time luminosity in 1992 & wastingChild & $\begin{array}{l}\text { Children under } 5 \text { years who are wasted } \\
\text { (weight-for-height; \%) }\end{array}$ \\
\hline nl2013 & Night-time luminosity in 2013 & severeWastingChild & $\begin{array}{l}\text { Children under } 5 \text { years who are severely wasted } \\
\text { (weight-for-height; \%) }\end{array}$ \\
\hline rainGrowth & $\begin{array}{l}\text { Percentage change in rainfall between } 1950 \mathrm{~s} \\
\text { and } 2000 \mathrm{~s}\end{array}$ & BMIwomeLow & $\begin{array}{l}\text { Women whose body mass index (BMI) is below } \\
\left.\text { normal (BMI }<18.5 \mathrm{~kg} / \mathrm{m}^{2} ; \%\right)\end{array}$ \\
\hline tempGrowth & $\begin{array}{l}\text { Percentage change in temperature between } \\
1950 \text { s and } 2000 \mathrm{~s}\end{array}$ & BMImenbeLow & $\begin{array}{l}\text { Men whose BMI is below normal } \\
\quad\left(\mathrm{BMI}<18.5 \mathrm{~kg} / \mathrm{m}^{2} ; \%\right)\end{array}$ \\
\hline folicAcid & $\begin{array}{l}\text { Mothers who consumed iron folic acid for } \\
100 \text { days or more when they were pregnant }\end{array}$ & BMIwomenHigh** & $\begin{array}{l}\text { Women who are overweight or obese } \\
\qquad\left(\mathrm{BMI} \geq 25.0 \mathrm{~kg} / \mathrm{m}^{2} ; \%\right)\end{array}$ \\
\hline IodizedSalt & Households using iodized salt (\%) & bloodsugarHighF & $\begin{array}{l}\text { High blood sugar level among women } \\
\qquad(>140 \mathrm{mg} / \mathrm{dl} ; \%)\end{array}$ \\
\hline HealthInsurance & $\begin{array}{l}\text { Households with any member covered by a } \\
\text { health scheme or health insurance }(\%)\end{array}$ & bloodsugarHighM & $\begin{array}{l}\text { High blood sugar level among men } \\
\qquad(>140 \mathrm{mg} / \mathrm{dl} ; \%)\end{array}$ \\
\hline female10yrsEdu & $\begin{array}{l}\text { Women with } 10 \text { or more years of } \\
\text { schooling }(\%)\end{array}$ & hypertensionF & $\begin{array}{l}\text { Hypertension prevalence in adult females } \\
\text { (NFHS-4) }\end{array}$ \\
\hline antenatalTerm 1 & $\begin{array}{l}\text { Mothers who had antenatal check-up in the } \\
\text { first trimester }(\%)\end{array}$ & hypertensionM & $\begin{array}{l}\text { Hypertension prevalence in adult males } \\
\text { (NFHS-4) }\end{array}$ \\
\hline
\end{tabular}

**BMI men high missing from the data table.

Table 2. Recoded variable definitions for the regression models

\begin{tabular}{lll}
\hline Effect & Variable & \\
\hline Random & District & District \\
Fixed & ChildAge & Child age (years) \\
& HFA & $\begin{array}{l}\text { Height for age (HFA) standard deviation } \\
\text { (WHO standard) }\end{array}$ \\
& MotherEd & Mother's education level \\
MotherAge & Mother's age at first birth \\
MotherLit & Mother's literacy level \\
Deliv & Place of delivery \\
Hb & Child's altitude-adjusted haemoglobin (Hb) \\
& level \\
PrecBI & Preceding birth interval (BI) \\
Water & Availability of improved water source \\
Toilet & Availability of toilet facility \\
Sex & Sex of child \\
Wealth & Household wealth index \\
RurUrb & Rural/urban designation \\
Antenat & Number of antenatal visits during pregnancy \\
Postnat & Baby postnatal check-up within 2 months \\
& (yes/no) \\
Diarrhoea & Had diarrhoea recently \\
\hline
\end{tabular}

$(\text { Table } 1)^{8,9}$. For each set of variables and districts, we used principal component analysis (PCA) in Python v3 scipy.stats package to reduce dimensionality of the da- taset and explore relationships among the variables and among the districts.

To assess the correlation among the variables and districts, as well as statistical significance of these correlations, we used the Spearman rank correlation method implemented in Python v3 scipy.stats package to correlate all variables with one another, or all districts with each other. We quantified significant correlations by indicating ' $* *$ ' when significance of the Spearman rank correlation reached $P \leq 8 \times 10^{-5}$ and '*' when $P \leq 0.01$ for correlation between variables. For correlation between districts, '**, denoted a significance of $P \leq 5.56 \times 10^{-5}$ (Figures 1 and 2).

To account for the correlations among coastal districts and stunting/wasting prevalence, we also applied mixed linear models to assess variation in the significance of contributors to childhood stunting for Karnataka as a whole and for the districts. We incorporated socio-economic and household factors into the regression model (Table 2). At the state level of Karnataka, a model was run examining the relationship between child height for age (HFA) standard deviation and the fixed effects found in Table 2. The outcome variable was child HFA for the $j$ th child born in district $i, I=1, \ldots, 30$. The model was 


\section{RESEARCH ARTICLES}

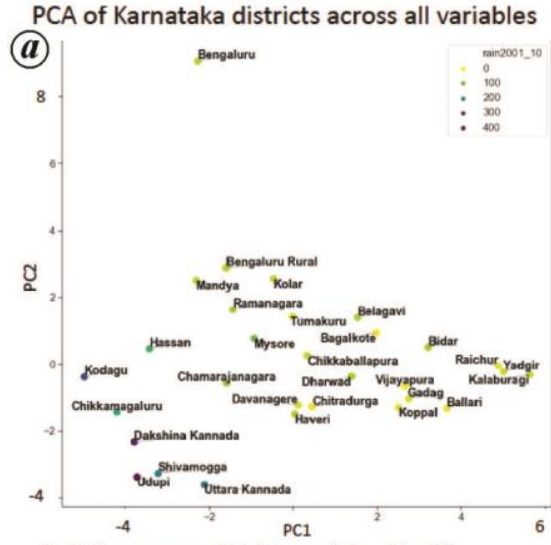

Variation among districts explained by PCS

(b)

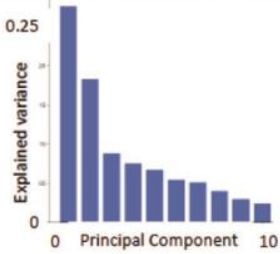

(c)

Spearman rank correlations between districts in Karnataka

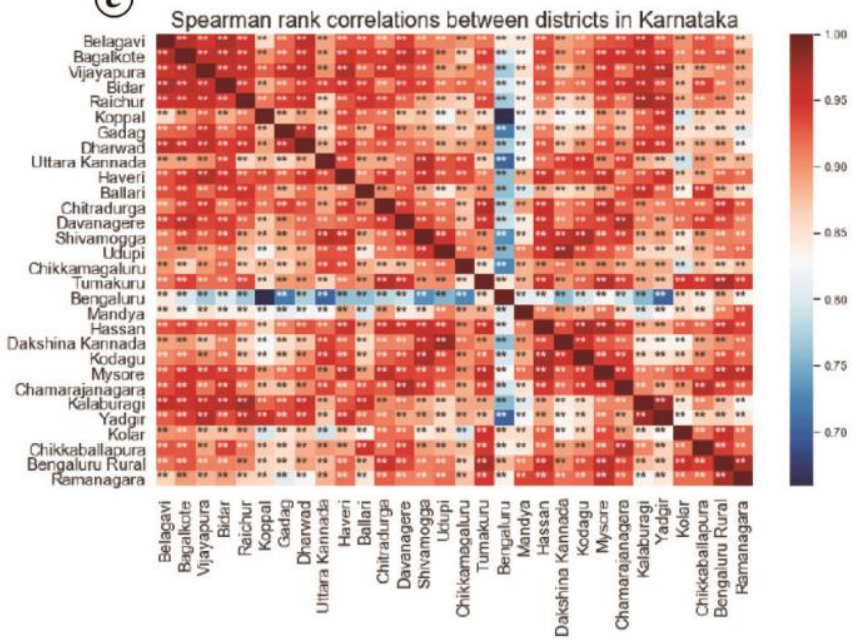

Figure 1. Principal component analysis (PCA) and Spearman rank correlation of all the districts in Karnataka, based on variables in Table 1. $\boldsymbol{a}$, The first two principal components (PCs), with each district coloured according to rainfall levels in 2001-10. $\boldsymbol{b}$, The proportion of variance explained by the PCs. $\boldsymbol{c}$, Spearman rank correlation among districts, with asterisks indicating significant correlations $\left(* * P \leq 5.56 \times 10^{-5}\right)$.

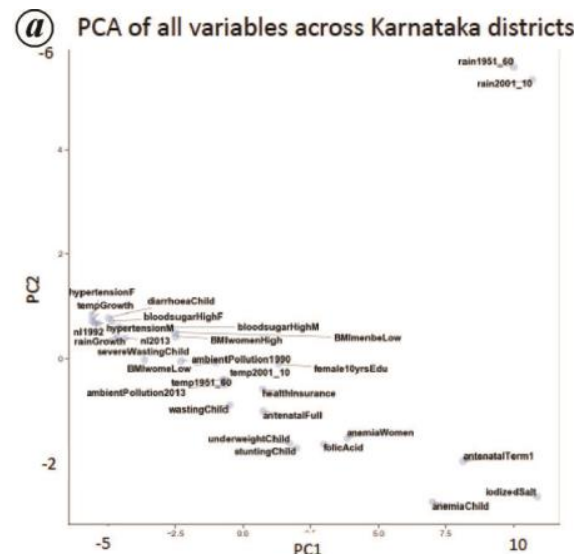

(b)

ariation among variables explained by PCs
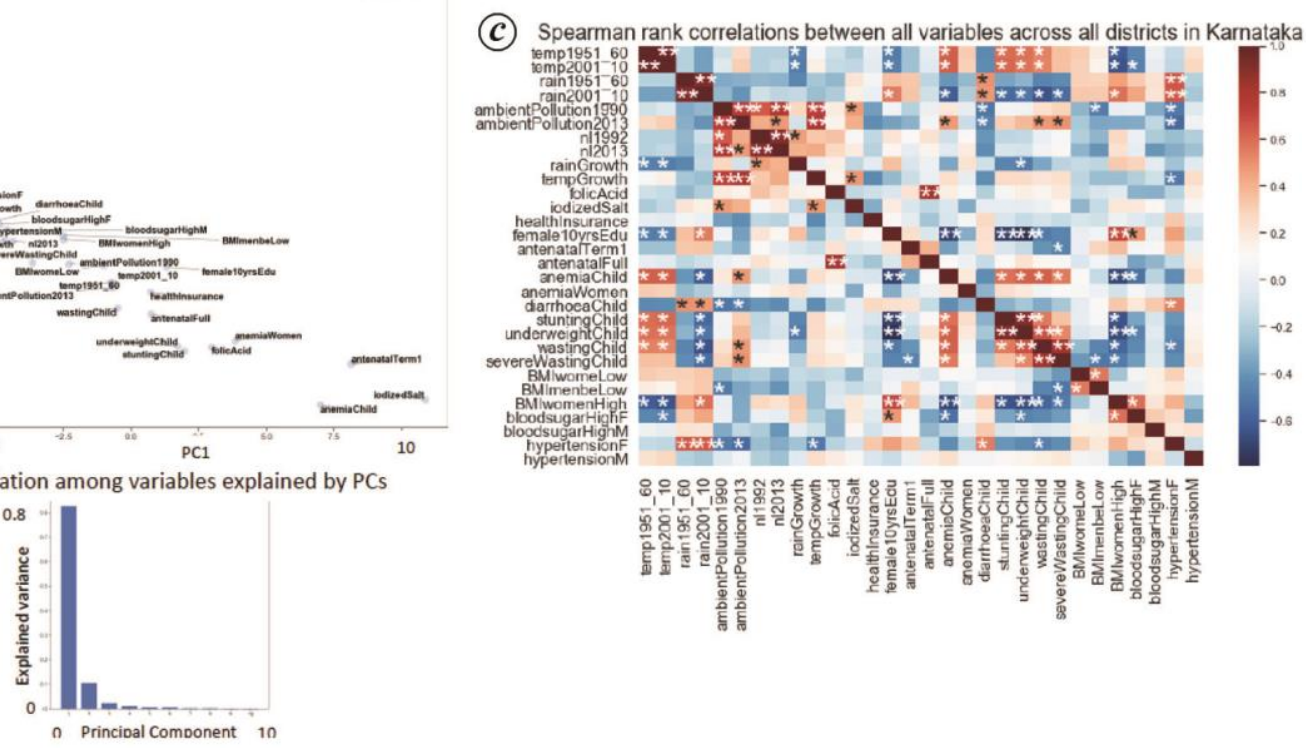

Figure 2. PCA and Spearman rank correlation of all the variables across districts in Karnataka, based on variables in Table 1. $\boldsymbol{a}$, The first two PCs. $\boldsymbol{b}$, The variance accounted for by the PCs. $\boldsymbol{c}$, Spearman rank correlation among districts, with asterisks indicating significant correlations $\left(* * P \leq 8 \times 10^{-5}\right.$ and $\left.* P \leq 0.01\right)$.

estimated with the following fixed effects: child's age, mother's education level, mother's age at first birth, mother's literacy level, place of delivery, child's altitudeadjusted haemoglobin $(\mathrm{Hb})$ level, preceding birth interval, availability of improved water source, availability of toilet facility, sex of the child, household wealth index, rural/urban designation, number of antenatal visits during pregnancy, whether or not a postnatal check-up was completed within two months, and recent occurrence of child diarrhoea. District was included as a random effect in 
order to account for random, potentially unobservable differences between districts, and provide a picture of the state as a whole.

$$
\begin{aligned}
\text { HFA }_{i j}= & \beta_{0}+\beta_{1} \text { ChildAge }_{i j}+\beta_{2} \text { MotherEd }_{i j} \\
& +\beta_{3} \text { MotherAge }_{i j}+\beta_{4} \text { MotherLit }_{i j}+\beta_{5} \text { Deliv }_{i j} \\
& +\beta_{6} \mathrm{Hb}_{i j}+\beta_{7} \text { PrecBI }_{i j}+\beta_{8} \text { Water }_{i j}+\beta_{9} \text { Toilet }_{i j} \\
& +\beta_{10} \text { Sex }_{i j}+\beta_{11} \text { Wealth }_{i j}+\beta_{12} \text { RurUrb }_{i j} \\
& +\beta_{13} \text { Antenat }_{i j}+\beta_{14} \text { Postnat }_{i j}+\beta_{15} \text { Diarrhoea }_{i j} \\
& + \text { District }_{i}+\varepsilon_{i j} .
\end{aligned}
$$

Statistical significance was determined using a type-III ANOVA analysis with the Kenward-Roger method of degrees of freedom approximation. Mixed linear models were run and analysed in RStudio v. 3.5.2. We used the package 'readstata13' to import data, packages 'lme4', 'car' and 'lmerTest' to run the mixed linear model, and packages 'effect' and 'emmeans' to plot the results and interaction effects of the model.

For district-level analyses, we separated the districts into 'high' and 'low' rainfall areas by implementing cut-offs for mean annual rainfall for 2001-10 (Table 1). Low-rainfall districts had annual rainfall levels $<70 \mathrm{~cm}$, whereas high-rainfall areas were those with $>140 \mathrm{~cm}$ of rainfall each year.

The same model was run separately for the districts with the highest rainfall levels in the state (districts with rainfall >140 cm: Uttara Kannada, Udupi, Dakshina Kannada, Kodagu, Shimoga and Chikkamagaluru), as well as the districts with the lowest rainfall levels (districts with rainfall $<70 \mathrm{~cm}$ : Bagalkote, Koppal, Chitradurga, Vijayapura, Ballari, Raichur, Gadag, Tumakuru, Davanagere, Yadgir, Chikkaballapura, Kalaburagi, Kolar and Mandya $)^{10}$. Rainfall data were obtained from AidData GEO for 2001-10.

Given the significant relationship of preceding birth interval, altitude-adjusted haemoglobin level, and child age and child HFA in the three statistical tests, interaction effect models were developed for the state as a whole, as well as the wettest and driest districts considering all other previous fixed effects as potential interaction effects.

$$
\begin{aligned}
\text { HFA }_{i j}= & \beta_{0}+\beta_{1} \operatorname{PrecBI}_{i j}+\beta_{1} \operatorname{PrecBI}_{i j} \beta_{2} \text { ChildAge }_{i j} \\
& +\beta_{1} \operatorname{PrecBI}_{i j} \beta_{3} \text { MotherEd }_{i j} \\
& +\beta_{1} \operatorname{PrecBI}_{i j} \beta_{4} \text { MotherAge }_{i j} \\
& +\beta_{1} \operatorname{PrecBI}_{i j} \beta_{5} \text { MotherLit }_{i j}+\beta_{1} \operatorname{PrecBI}_{i j} \beta_{6} \operatorname{Deliv}_{i j} \\
& +\beta_{1} \operatorname{PrecBI}_{i j} \beta_{7} \mathrm{Hb}_{i j}+\beta_{1} \operatorname{PrecBI}_{i j} \beta_{8} \text { Water }_{i j} \\
& +\beta_{1} \operatorname{PrecBI}_{i j} \beta_{9} \text { Toilet }_{i j}+\beta_{1} \operatorname{PrecBI}_{i j} \beta_{10} \operatorname{Sex}_{i j} \\
& +\beta_{1} \operatorname{PrecBI}_{i j} \beta_{11} \text { Wealth }_{i j}+\beta_{1} \operatorname{PrecBI}_{i j} \beta_{12} \operatorname{RurUrb}_{i j}
\end{aligned}
$$

$+\beta_{1}$ PrecBI $_{i j} \beta_{13}$ Antenat $_{i j}+\beta_{1}$ PrecBI $_{i j} \beta_{14}$ Postnat $_{i j}$

$+\beta_{1}$ PrecBI $_{i j} \beta_{15}$ Diarrhoea $_{i j}+$ District $_{i}+\varepsilon_{i j}$,

$$
\begin{aligned}
\text { HFA }_{i j}= & \beta_{0}+\beta_{1} \mathrm{Hb}_{j}+\beta_{1} \mathrm{Hb}_{i j} \beta_{2} \text { ChildAge }_{i j} \\
& +\beta_{1} \mathrm{Hb}_{i j} \beta_{3} \text { MotherEd }_{i j}+\beta_{1} \mathrm{Hb}_{i j} \beta_{4} \text { MotherAge }_{i j} \\
& +\beta_{1} \mathrm{Hb}_{i j} \beta_{5} \text { MotherLit }_{i j}+\beta_{1} \mathrm{Hb}_{i j} \beta_{6} \text { Deliv }_{i j} \\
& +\beta_{1} \mathrm{Hb}_{i j} \beta_{7} \text { PrecBI }_{i j}+\beta_{1} \mathrm{Hb}_{i j} \beta_{8} \text { Water }_{i j} \\
& +\beta_{1} \mathrm{Hb}_{i j} \beta_{9} \text { Toilet }_{i j}+\beta_{1} \mathrm{Hb}_{i j} \beta_{10} \text {Sex}_{i j} \\
& +\beta_{1} \mathrm{Hb}_{i j} \beta_{11} \text { Wealth }_{i j}+\beta_{1} \mathrm{Hb}_{i j} \beta_{12} \text { RurUrb}_{i j} \\
& +\beta_{1} \mathrm{Hb}_{i j} \beta_{13} \text { Antenat }_{i j}+\beta_{1} \mathrm{Hb}_{i j} \beta_{14} \text { Postnat }_{i j} \\
& +\beta_{1} \mathrm{Hb}_{i j} \beta_{15} \text { Diarrhoea }_{i j}+\text { District }_{i}+\varepsilon_{i j},
\end{aligned}
$$

$$
\begin{aligned}
\text { HFA }_{i j}= & \beta_{0}+\beta_{1} \text { ChildAge }_{j}+\beta_{1} \text { ChildAge }_{i j} \beta_{2} \mathrm{Hb}_{i j} \\
& +\beta_{1} \text { ChildAge }_{i j} \beta_{3} \text { MotherEd }_{i j} \\
& +\beta_{1} \text { ChildAge }_{i j} \beta_{4} \text { MotherAge }_{i j} \\
& +\beta_{1} \text { ChildAge }_{i j} \beta_{5} \text { MotherLit }_{i j} \\
& +\beta_{1} \text { ChildAge }_{i j} \beta_{6} \text { Deliv }_{i j} \\
& +\beta_{1} \text { ChildAge }_{i j} \beta_{7} \text { PrecBI }_{i j} \\
& +\beta_{1} \text { ChildAge }_{i j} \beta_{8} \text { Water }_{i j} \\
& +\beta_{1} \text { ChildAge }_{i j} \beta_{9} \text { Toilet }_{i j} \\
& +\beta_{1} \text { ChildAge }_{i j} \beta_{10} \text { Sex }_{i j} \\
& +\beta_{1} \text { ChildAge }_{i j} \beta_{11} \text { Wealth }_{i j} \\
& +\beta_{1} \text { ChildAge }_{i j} \beta_{12} \text { RurUrb }_{i j} \\
& +\beta_{1} \text { ChildAge }_{i j} \beta_{13} \text { Antenat }_{i j} \\
& +\beta_{1} \text { ChildAge }_{i j} \beta_{14} \text { Postnat }_{i j} \\
& +\beta_{1} \text { ChildAge }_{i j} \beta_{15} \text { Diarrhoea }_{i j}+\text { District }_{i}+\varepsilon_{i j} .
\end{aligned}
$$

\section{Results}

Karnataka shows variability in stunting prevalence among districts, with the highest coefficient of variation among middle-SDI states in India ${ }^{6}$. Furthermore, the state shows high variability in other aspects of CGF, like severe wasting (Figure 3). Therefore, we sought to carry out PCA on features of child and maternal health, as well as some environmental factors, to determine the relationships between the various districts, and among the variables included in this analysis.

\section{Bengaluru is distinct from other Karnataka districts for environment and child health risk factors}

We found that, based on a mapping of the first two principal components (PCs), Bengaluru appears to be distinct 
from all the other districts (Figure 1). The first two PCs account for $50 \%$ of the total variance among districts (Figure $1 b$ ). The other districts appear visually to cluster according to rainfall levels (Figure $1 a$ ), suggesting similarities in PC contribution based on climate. Spearman rank correlation of each district with the other districts, based on the information provided in Table 1 shows that Bengaluru is yet again distinct. Here, we find that in most districts the values corresponding to the variables in Table 1 correlate with each other, with a few notable exceptions: Kolar does not show a statistically significant correlation with Uttara Kannada, and Bengaluru does not show statistically significant correlations with Koppal, Gadag, Uttara Kannada, Shivamogga, Udupi, Chikkamagaluru and Dakshina Kannada districts. These correlations are all negative and not statistically significant. Thus, these analyses showed that all the districts of Karnataka, with the notable exception of Bengaluru, show similarities based on climate, diet and health outcome metrics.

\section{Climate variables and child health-related variables form distinct groups}

We performed PCA on the variables as well (Figure 2). The first two PCs account for $>90 \%$ of the total variance among variables (Figure $2 b$ ). Figure $2 a$ using the first two PCs shows that rainfall and child anaemia form separate clusters, with rainfall being on a separate axis than the other variables. Figure $2 c$ shows statistically significant correlation with environmental factors like rainfall, temperature and ambient pollution for a number of healthrelated variables, which in turn seem to be significantly correlated $(P<0.01)$ with each other, particularly for variables related to child health (Figure 2). Stunting showed statistically significant correlation with underweight (positive) and female10yrsEdu (negative) at $P<8 \times 10^{-5}$
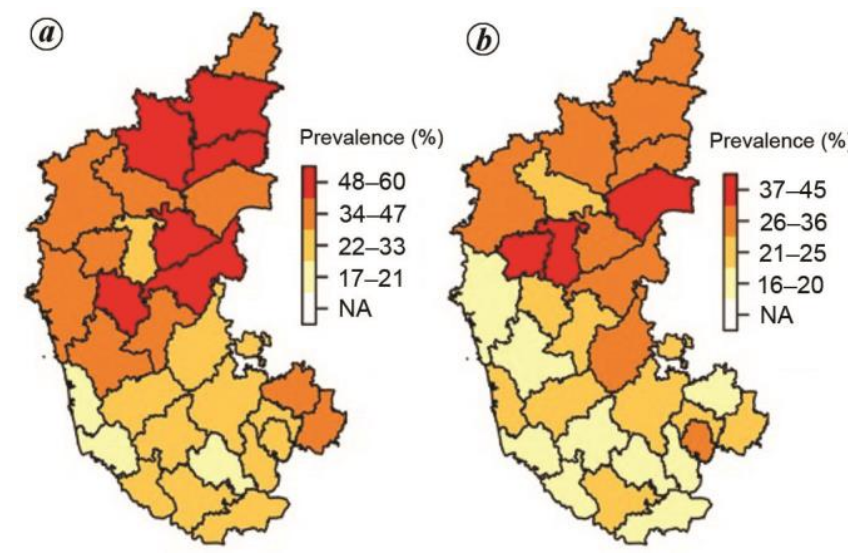

Figure 3. (a) Stunting and (b) wasting prevalence of children <5 years of age in Karnataka, India, based on National Family Health Survey-4 (NFHS-4) data. and with wasting (positive), the temperature variables (positive), BMI women high (negative) and childhood anaemia (positive) at a less stringent $P<0.01$.

We visualized the relationships among the child healthrelated variables to examine trends among districts (Figure 4). Stunting and diarrhoea did not appear to show any correlation - Gadag district, for example, appears to have the highest rate of diarrhoea but medium stunting prevalence, whereas Kalaburagi, Yadgir and Koppal districts have very high stunting prevalence $(>50 \%)$ but lower diarrhoea prevalence compared to Gadag (Figure $4 a$ ). Rainfall is not an adequate descriptor for the differences in prevalence as all four districts have similar rainfall levels. Severe wasting and anaemia, similarly, do not show a statistically significant or strong correlation with childhood stunting; once again, Gadag appears to be near the top for wasting and anaemia, but near the middle for stunting (Figure $4 d$ ). With anaemia, however, several states with high prevalence of stunting also show high anaemia prevalence. Finally, stunting and underweight show a strong, positive and statistically significant correlation; children who are stunted may also weigh less than their peers (Figure 4).

Figure 3 shows that the environmental factors like rainfall, temperature and ambient pollution show statistically significant correlation with a number of health-related variables, some of which showed significant correlation with each other. A few other reports of relationships among climate factors and childhood stunting suggest that while environmental differences likely account for much of the variation between districts, the relationship of these environmental variables with health variables indicates possible variation in stunting risk factors based on environment ${ }^{6,11}$. Therefore, we carried out mixed linear regression analyses on individual-level data from NFHS-4 to explore the relationship of environmental and health outcomes on childhood stunting.

\section{Multivariate regression analysis shows differences in factors that influence height-for-age in wet and dry districts, and in comparison to state-wide height-for-age}

Since stunting is a metric of HFA, we sought to understand the factors that contribute most significantly to child HFA in Karnataka. We carried out three separate mixed linear model analyses: a state-wide analysis, an analysis solely within the 'dry' districts, and in the 'wet' districts (Figure 5; Supplementary Table 1). The variables included were more expansive (Table 2) than those included in the PCA and Spearman rank correlation analyses (Table 1) to account for socio-economic factors and other variables that have been included in regression analyses in the literature ${ }^{12}$. The individual-level data from NFHS-4 were used, as opposed to district-aggregated data in previous sections. 

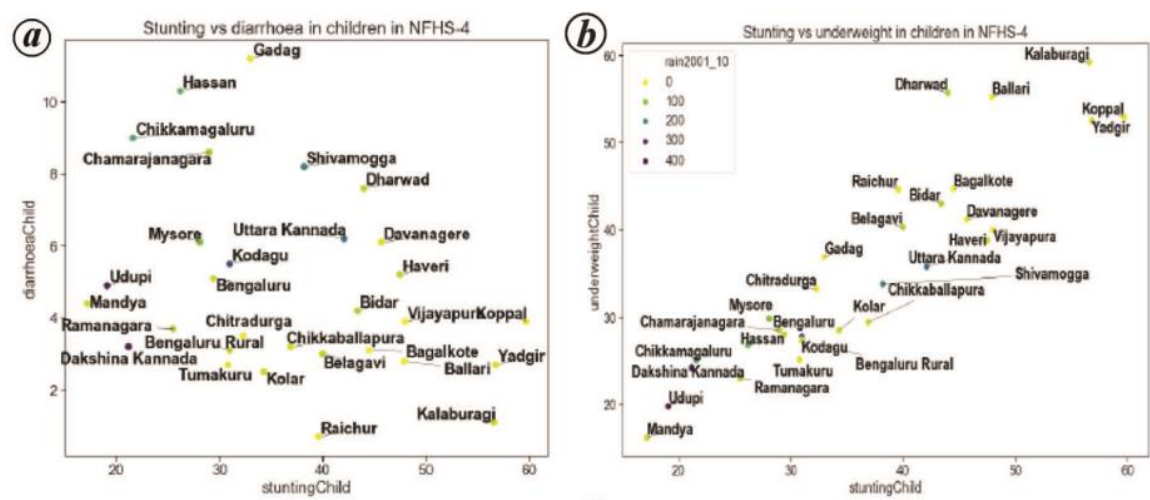

rain2001_10
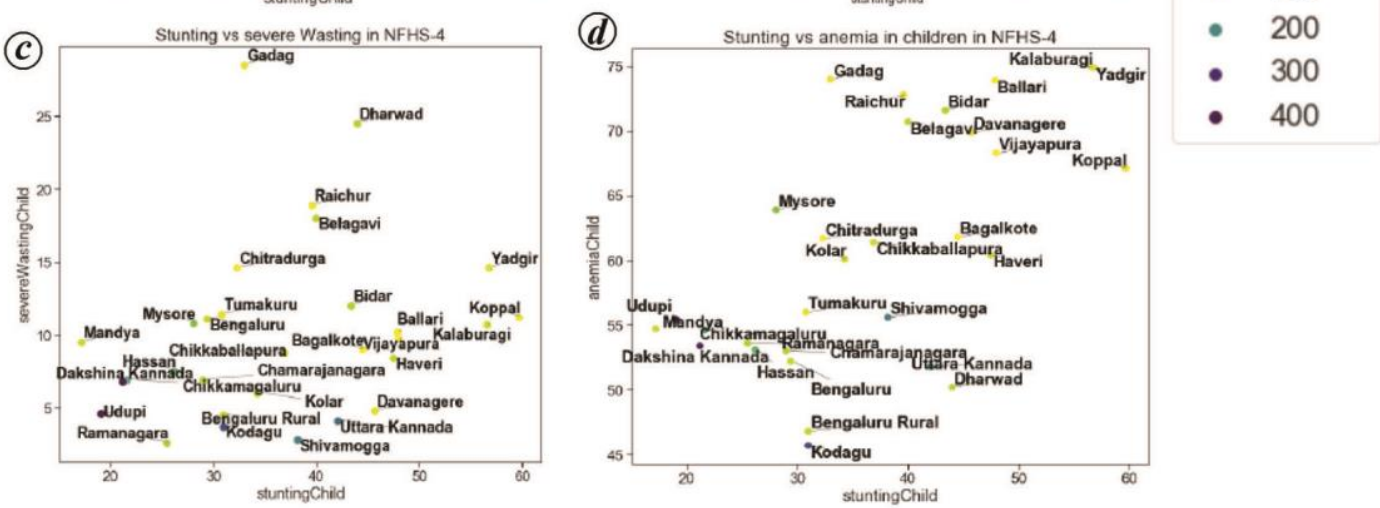

Figure 4. Correlation between variables related to child health: $(\boldsymbol{a})$ stunting and diarrhoea, $(\boldsymbol{b})$ underweight, $(\boldsymbol{c})$ severe wasting and $(\boldsymbol{d})$ anaemia.
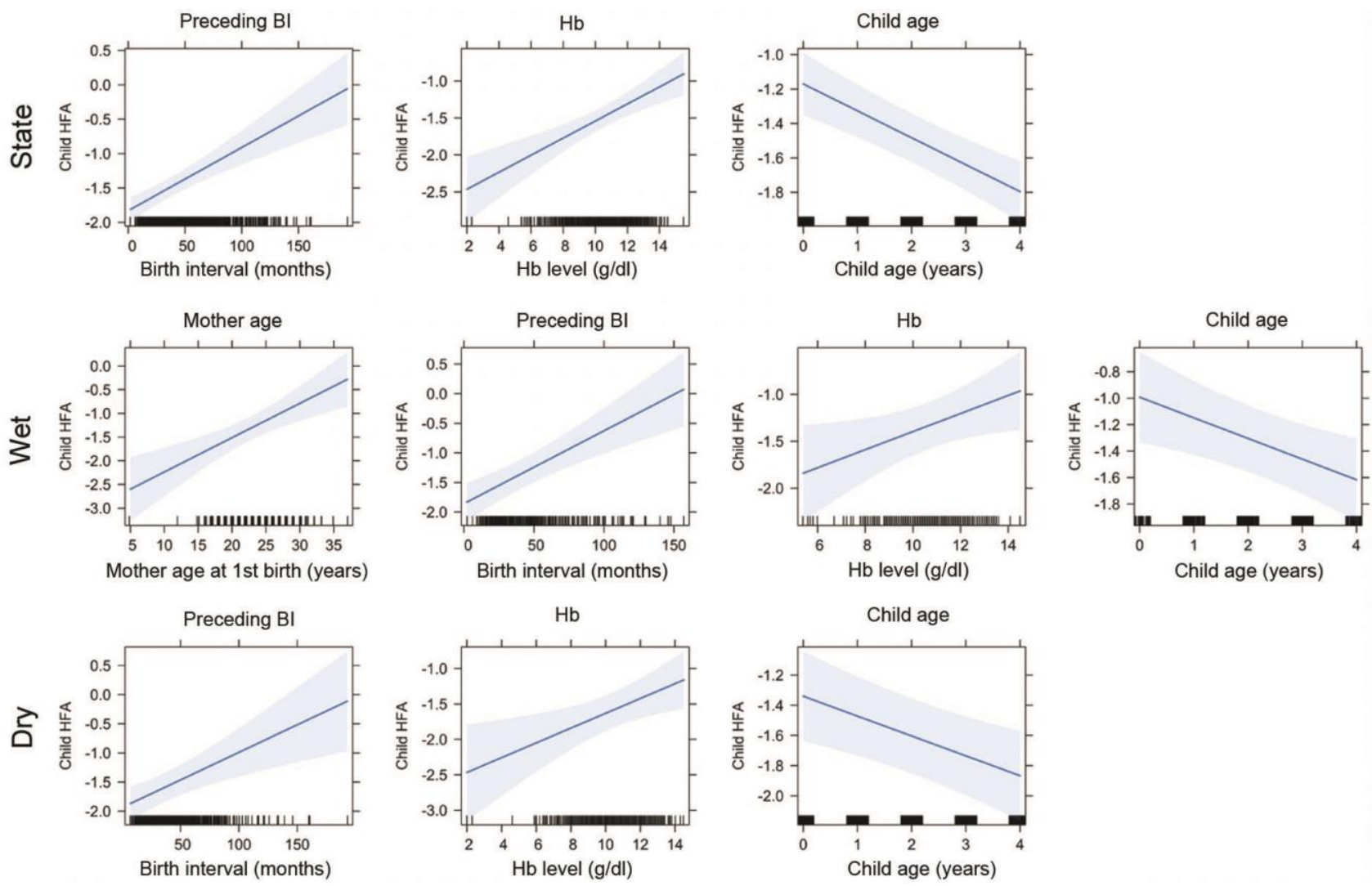

Figure 5. Variables showing statistically significant correlation with stunting in the analyses for entire Karnataka, and wet and dry districts in the state. Individual-level NFHS-4 data were used for the regression analyses. 


\section{RESEARCH ARTICLES}

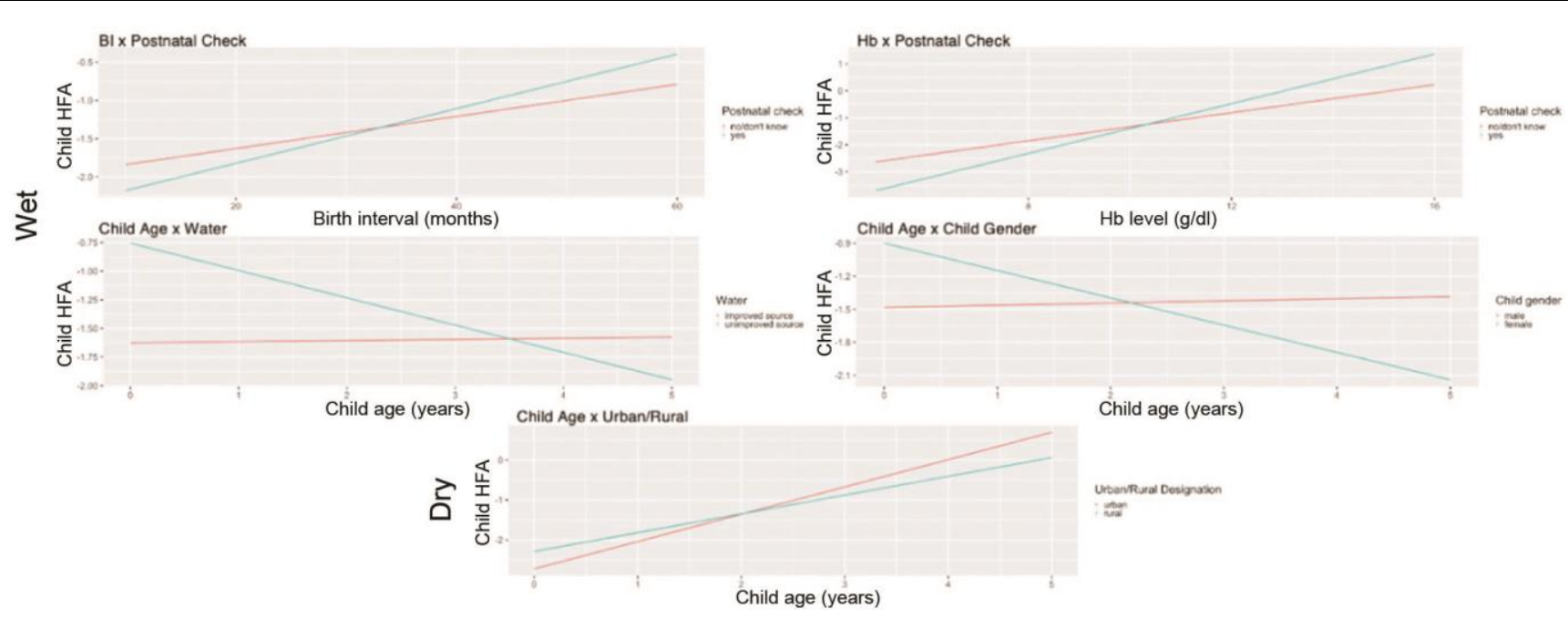

Figure 6. Interaction effects among variables and height for age among all districts in Karnataka, and wet and dry districts separately.

Table 3. $P$-values for multivariate regression analysis

\begin{tabular}{lll}
\hline Analysis & \multicolumn{1}{c}{ Correlation } & $P$-value \\
\hline State & Preceding BI $\sim$ child HFA & $<0.001$ \\
State & Hb $\sim$ child HFA & $<0.001$ \\
State & Child age $\sim$ child HFA & $<0.001$ \\
Wet & Mother age $\sim$ child HFA & $<0.001$ \\
Wet & Preceding BI $\sim$ child HFA & $<0.001$ \\
Wet & Hb $\sim$ child HFA & $<0.05$ \\
Wet & Child age $\sim$ child HFA & $<0.01$ \\
Dry & Preceding BI $\sim$ child HFA & $<0.001$ \\
Dry & Hb $\sim$ child HFA & $<0.01$ \\
Dry & Child age $\sim$ child HFA & $<0.01$ \\
\hline
\end{tabular}

In the state-wide analysis, we found that higher child $\mathrm{Hb}$ level and higher preceding birth interval were significantly positively correlated with higher child HFA $(P<0.001)$ (Figure 5). We also found a negative correlation for child age and HFA. The latter suggests that HFA decreases with higher age of the child.

For both the wet and dry districts, preceding birth interval and altitude-adjusted $\mathrm{Hb}$ level were significantly positively correlated with child HFA (Table 3), as in the state-level analysis (Figure 5). The wet districts also saw a significant negative correlation between maternal age at first birth and child HFA, which was not present in the state-wide or dry analyses.

As risk factors were similar across all levels of analysis but had some variance in significance, further interaction analyses were conducted.

Interaction effects among variables state-wide, and wet and dry districts show contextual differences

Interaction effects were evaluated for preceding birth interval, altitude-adjusted $\mathrm{Hb}$ level, and child age at the state-wide, wet and dry district levels. The state-level analysis was conducted both including and excluding Bengaluru, as this district appeared to behave as an outlier in the PCA findings. No significant interaction effects were found at the state level irrespective of whether Bengaluru was included.

Among the wet districts, the correlation between increased preceding birth interval and child HFA, and between increased $\mathrm{Hb}$ level and child HFA was significantly stronger for children who received a postnatal check-up within two months $(P<0.01$ and $P<0.05$ respectively) (Figure 6). In addition, the correlation increased child age and decreased child HFA was only true for households with unimproved water sources and for children who were female, although neither sex of the child nor water source showed significant main effects on child HFA $(P<0.05)$. For the dry districts, child age showed a significant interaction with urban/rural designation, with higher child age more strongly correlated with higher child HFA for urban areas $(P<0.05)$ (Figure 6).

\section{Discussion}

We have reported an analysis of the contributors to childhood stunting and HFA in Karnataka, India, with the view of understanding the role of rainfall in child health outcomes. We provide evidence for our hypothesis that different environments even within a single state can influence childhood stunting through mediating several risk factors.

The districts of Karnataka largely differed in contributors to the stunting burden when interaction effects were evaluated. However, $\mathrm{Hb}$ levels correlated with child HFA consistently across the districts.

This relationship likely reflects overall child health and advantageous family environment, with $\mathrm{Hb}$ and HFA both reflecting health status of the child. 
PCA shows that climate variables form a separate axis from health-related variables, showing that geographical environment may be independent from the health-related variables. While the PCA findings suggest that Bengaluru appears to be distinct from the other districts (Figure 2), this was not reflected in our regression interaction analyses. It is possible that Bengaluru differs from the other districts in ways that have not been accounted for in this study, and warrants further studies.

We also found that the districts with high rainfall showed distinct patterns of child health outcomes compared to the other districts, suggesting that climate may also have a significant effect. Climate associates with stunting outcomes through moderating unique interacting factors that differ based on rainfall. For example, higher child age was significantly correlated with lower HFA at all levels of analysis. Similar studies in Ethiopia, Kenya, Nepal and Vietnam suggest that this decreased HFA towards the older end of the critical development window reflects inadequate complementary feeding as children are weaned ${ }^{13-20}$. Unlike these countries, however, we found that in the wet districts in Karnataka, this inverse age-HFA correlation was only true for female children and those exposed to unimproved water sources, while this gender and water source difference was not present in the dry districts. These findings suggest that in certain districts of Karnataka, more attention must be directed towards gender balance in nutrition and greater access to clean water, particularly for older toddlers and potentially school-aged children.

The significant contribution of maternal age to stunting burden in the wet districts is also notable. Mothers who are older tend to have more decision-making power in the household, specifically in terms of equitable resource distribution $^{21-23}$. This aligns with our finding that in the wet districts, female children and those exposed to unimproved water sources see an age-related increase in stunting risk. Young mothers are more likely to demonstrate preference for the male child, such that daughters receive less food allocation as they are weaned, which manifests as an increased stunting burden as they approach 60 months. Increased risk of infectious disease in the wet districts exacerbates this burden, developing a confluence of risk factors unique to these districts. Identifying these interactions can help stakeholders design programmes in these regions which specifically empower mothers (and eventually fathers) to participate in their children's nutrition in an active and informed manner.

The results of this study suggest that policymakers should be cognizant of regional differences in stunting outcome and risk. Given the interaction variations seen in the wet and dry districts, state policymakers must collaborate with local governments and small NGOs to identify the initiatives that will be most effective for each region, instead of rolling out blanket programmes. For example, diarrhoea is connected to weather patterns in South India and is also a risk factor in stunting ${ }^{24,25}$. Specific interventions at particular times of the year may lower diarrhoea prevalence, which could help reduce risk to childhood stunting and other features of CGF. In addition to improving the efficiency of alleviating the stunting burden, this approach also has the potential to reduce costs by eliminating unnecessary expenditure that does not affect CGF outcomes in the wet or dry districts.

Our results also fit into a greater story for India. Climate is just one criterion of distinguishing regions and unique risk factors. Other methods of stratification include religion and cultural background, proximity to bodies of water and supply chains, and access to advanced health centres. Biologists, physicians and clinicians must consider these variations in stunting risk and risk factors, and liaise with the government officials to identify the most efficacious and cost-effective interventions.

1. Bhutta, Z. A. et al., Evidence-based interventions for improvement of maternal and child nutrition: what can be done and at what cost? Lancet, 2013, 382, 452-477.

2. Malnutrition in Children-UNICEF Data, 2021; https://data. unicef.org/topic/nutrition/malnutrition/ (accessed on 10 July 2021).

3. Menon, P., Headey, D., Avula, R. and Nguyen, P. H., Understanding the geographical burden of stunting in India: a regressiondecomposition analysis of district-level data from 2015-16. Matern. Child Nutr., 2018, e12620.

4. Pingali, P., Aiyar, A., Abraham, M. and Rahman, A., Transforming Food Systems for a Rising India, Palgrave Macmillan, 2019, 1 st edn.

5. Li, Z., Kim, R., Vollmer, S. and Subramanian, S. V., Factors associated with child stunting, wasting and underweight in 35 low- and middle-income countries. JAMA Netw. Open, 2020, 3, e203386.

6. India state-level disease burden initiative CGF collaborators, mapping of variations in child stunting, wasting and underweight within the states of India: the global burden of disease study 2000 2017. EClinicalMedicine, 2020, 22, 100317.

7. Mohanty, S. K., Mishra, N. R., Khan, J., Vasishtha, G. and Mishra, U. S., State of health in the districts of India. In The Demographic and Development Divide in India: A District-Level Analyses (eds Mohanty, S. K. et al.), Springer, Singapore, 2019, pp. 329-373.

8. Goodman, S., Ben Yishay, A., Runfola, D, Overview of the geo framework. AidData, 2017.

9. IIPS and ICF, National Family Health Survey (NFHS-4), 201516: India. International Institute for Population Sciences, Mumbai, 2017.

10. Annual Seasonal Rainfall and Area Coverage during 2017 in Karnataka, Directorate of Economics and Statistics, Government of Karnataka, 2018.

11. Cooper, M. W. et al., Mapping the effects of drought on child stunting. Proc. Natl. Acad. Sci. USA, 2019, 116, 17219-17224.

12. Jayachandran, S. and Pande, R., Why are Indian children so short? Am. Econ. Rev., 2017, 107(9), 2600-2629.

13. Abera, L., Dejene, T. and Laelago, T., Magnitude of stunting and its determinants in children aged 6-59 months among rural residents of Damot Gale district; southern Ethiopia. BMC Res. Notes, 2018, 11, 557.

14. Mengistu, K., Alemu, K. and Destaw, B., Prevalence of malnutrition and associated factors among children aged 6-59 months at Hidabu Abote district, North Shewa, Oromia regional state. J. Nutr, Disord. Therapy, 2013, 6, 1-8. 
15. Moges, B., Feleke, A., Meseret, S. and Doyore, F., Magnitude of stunting and associated factors among 6-59 months old children in Hossana town, southern Ethiopia. J. Clin. Res. Bioeth., 2015, 6, 1.

16. Asres, G. and Eidelman, A. I., Nutritional assessment of Ethiopian Beta-Israel children: a cross-sectional survey. Breastfeed. Med., 2011, 6, 171-176.

17. Adhikari, R. P., Shrestha, M. L., Acharya, A. and Upadhaya, N., Determinants of stunting among children aged 0-59 months in Nepal: findings from Nepal Demographic and health Survey, 2006, 2011 and 2016. BMC Nutr., 2019, 5, 37.

18. Khan, N. C., Tuyen, L. D., Ngoc, T. X., Duong, P. H. and Khoi, H. H., Reduction in childhood malnutrition in Vietnam from 1990 to 2004. Asia Pac. J. Clin. Nutr., 2007, 16, 274-278.

19. Hien, N. N. and Kam, S., Nutritional status and the characteristics related to malnutrition in children under five years of age in Nghean, Vietnam. J. Prev. Med. Public Health, 2008, 41, 232 240 .

20. Ulak, M., Chandyo, R. K., Mellander, L., Shrestha, P. S. and Strand, T. A., Infant feeding practices in Bhaktapur, Nepal: a cross-sectional, health facility based survey. Int. Breastfeed. J., 2012, 7, 1.

21. Munro, A., Kebede, B., Tarazona-Gomez, M. and Verschoor, A., Autonomy and efficiency. An experiment on household decisions in two regions of India. J. Jpn. Int. Econ., 2014, 33, 114-133.

22. Desai, S. and Andrist, L., Gender scripts and age at marriage in India. Demography, 2010, 47, 667-687.
23. Nahar, S. and Pillai, V. K., Girl child discrimination and child stunting in India: what can be done? Int. J. Commun. Soc. Develop., 2019, 1, 75-86.

24. Mertens, A. et al., Associations between high temperature, heavy rainfall, and diarrhea among young children in rural Tamil Nadu, India: a prospective cohort study. Environ. Health Perspect., 2019, 127, 47004.

25. Guerrant, R. L., DeBoer, M. D., Moore, S. R., Scharf, R. J. and Lima, A. A. M., The impoverished gut - a triple burden of diarrhoea, stunting and chronic disease. Nat. Rev. Gastroenterol. Hepatol., 2013, 10, 220-229.

ACKNOWLEDGEMENTS. We thank Prof. H. Sharat Chandra (Centre for Human Genetics, Bengaluru) for his thorough review and comments on the article; Dr Lynn M. Johnson (Tata Cornell Institute, Cornell University, Ithaca, NY, USA) for her statistical expertise and advice and Dr Andaleeb Rahman (Statistical Consulting Unit, Cornell University, Ithaca, NY, USA) for providing the NFHS-4 data. We also thank the Tata Cornell Institute, Cornell University, USA, for funding the research.

Received 30 October 2020; revised accepted 20 June 2021

doi: $10.18520 / \mathrm{cs} / \mathrm{v} 121 / \mathrm{i} 4 / 502-510$ 